\title{
Utilização de substratos orgânicos na produção de mudas de Eugenia uniflora L.
}

Use of organic substrates on the production of seedlings of Eugenia uniflora L.

\author{
Alan Richar Freitas Marques \\ Alice Lemos Costa \\ Amanda Oliveira Travessas \\ Alexandra Augusti Boligon \\ Silvane Vestena
}

Universidade Federal do Pampa - Unipampa - São Gabriel - Rio Grande do Sul - Brasil

\section{Resumo}

O objetivo deste trabalho foi avaliar o efeito de diferentes substratos na produção e qualidade de mudas de Eugenia uniflora DC. Os tratamentos foram compostos por quatro substratos, sendo: S1) $100 \%$ substrato comercial Plantmax ${ }^{\circledR}$; S2) $50 \%$ substrato comercial Plantmax ${ }^{\circledR}+50 \%$ substrato cama de equino; S3) $50 \%$ substrato comercial Plantmax ${ }^{\circledR}+50 \%$ resíduo do tratamento de esgoto e S4) $50 \%$ substrato comercial Plantmax ${ }^{\oplus}+50 \%$ resíduo do tratamento de água, sendo realizado análise de alguns parâmetros físico-químico dos substratos. Os tratamentos foram arranjados em delineamento inteiramente casualizado, com cinco repetições com 25 sementes cada. A cada três dias durante 90 dias foram realizadas a contagem de plântulas que emergiram para posterior calculo de índice de velocidade de emergência. Decorridos 180 dias após a semeadura foi calculada a porcentagem de emergência e as demais características biométricas, tais como: comprimento da parte aérea e do sistema radicular, diâmetro do coleto, número de folhas, massas fresca e seca da parte aérea, radicular e total e, ainda foi calculado o índice de qualidade de Dickson, bem como foi quantificado o teor de alguns macro e micronutrientes do sistema radicular, do caule e das folhas. Diante dos resultados obtidos foi observado que o substrato composto de resíduo do tratamento de água se mostrou efetivo a obtenção de mudas viáveis para plantio a campo.

\section{Abstract}

The objective of this study was to evaluate the effects the different substrates on the production and quality of Eugenia uniflora DC. seedlings. Treatments were composed by four substrates, where: S1) $100 \%$ of commercial substrate Plantmax ${ }^{\circledR}$; S2) $50 \%$ of commercial substrate Plantmax $^{\circledR}+50 \%$ of equine bed substrate; S3) $50 \%$ of commercial substrate Plantmax ${ }^{\circledR}+50 \%$ of sewer treatment residues and S4) $50 \%$ of commercial substrate Plantmax ${ }^{\circledR}+50 \%$ of water treatment residues. Treatments were established following an entirely randomized design with five repetitions of 25 seeds each. Every three days during 90 days, the emerged seedlings were counted in order to determinate the emergency speed index. After 180 days of sowing the percentage of emergency and other biometric characteristics such as fronds and roots length, collar diameter, number of leaves, fresh and dry weight of fronds, roots and total plant were determined. Moreover, Dickson Quality Index was calculated as well as macro and micronutrients concentration of roots, stalk and leaves were quantified. Analyzing the results, the substrate composed by water treatment residues showed to be effective for obtaining viable seedling for the field.

\section{Palavras-chave}

Características morfológicas. Sementes. Substratos.

\section{Keywords}

Morphological characteristics. Seeds. Substrate. 


\section{Introdução}

Originária do Brasil, a pitangueira (Eugenia uniflora L.), Myrtaceae, devido à sua adaptabilidade encontra-se nas mais variadas regiões do Brasil e do mundo (Abreu et al., 2005; Silva, 2006; Elli et al., 2013); é considerada espécie ornamental e pode ser utilizada no paisagismo (Lorenzi, 2008); valorizada pelas suas folhas e frutos com óleos essenciais, sais minerais e vitaminas, apresenta potencial de exploração pelas indústrias alimentícias, cosméticas e medicinais (Lira Junior et al., 2007; Elli et al., 2013; Alexandre et al., 2014; Peña et al., 2015).

O principal método de propagação para a pitangueira é via semente, portanto a qualidade da muda torna-se um fator predisponente ao vigor das plantas, além da futura produtividade e vida útil do pomar (Chalfune e Pio, 2002; Abreu et al., 2005). Neste contexto, a qualidade do substrato é um dos fatores responsáveis por condicionar padrões de qualidade das mudas no viveiro (Wendling et al., 2002; Elli et al., 2013).

O substrato apresenta papel fundamental, pois deve fornecer às mudas todas as condições químicas, físicas e biológicas, para um crescimento saudável, oferecendo assim condições de transformar seu potencial genético em produtividade (Kämpf e Fermino, 2000; Silva et al., 2017). Simões et al. (2012) relatam que deve-se reger esforços para a utilização de substratos que permitam o maior desenvolvimento e qualidade de mudas e, Mendonça et al. (2014) relatam que muitas práticas têm sido realizadas para melhorar a qualidade e reduzir os custos de produção das mudas, tal como a utilização de materiais renováveis. Esses materiais são fontes de nutrientes, e ainda são uma alternativa para a destinação dos resíduos, diminuindo os possíveis problemas socioambientais causados por estes, podendo ser uma saída efetiva para a redução dos altos custos de insumos necessários para produção de mudas florestais (Trazzi et al., 2013).

Os resíduos industriais, urbanos ou agroindustriais, em especial o lodo de esgoto e tratamento de água, são alternativas viáveis para serem utilizados como mistura de substrato, pois grandes volumes destes produtos são gerados e representam um problema ambiental quanto a uma destinação apropriada. Portanto, a utilização desses resíduos como componente do substrato, além de propiciar uma economia na produção de mudas, garante um destino apropriado, evitando que seu acúmulo se torne um problema ambiental (Caldeira et al., 2014).

Considerando a importância do tema, é primordial que ocorra mais estudos em relação aos substratos, uma vez que podem surgir novas alternativas para sua formulação e utilização, diminuindo o custo de produção e aumentando a qualidade das mudas levadas para plantio no campo (Faustino et al., 2005; Scheer et al., 2010; Caldeira et al., 2014).

Portanto, o objetivo deste trabalho foi avaliar o efeito de quatro diferentes substratos na produção e qualidade de mudas de Eugenia uniflora L..

\section{Material e métodos}

O experimento foi conduzido em casa de vegetação de $256 \mathrm{~m}^{2}$ com as seguintes dimensões: $8 \times 32 \times 4 \mathrm{~m}$ (largura $\times$ comprimento $\times$ altura) coberta com polietileno de baixa densidade (PeBD) de $100 \mu \mathrm{m}$, sombrite de 50\%, e sistema automático de irrigação por microaspersão na Universidade Federal do Pampa - Campus São Gabriel (3020'11" S e 5419'11" W, 114 m de altitude), município de São Gabriel, Rio Grande do Sul.

Os frutos de pitangueira foram coletados no início de novembro de 2015 em pomar doméstico situado no Município de São Gabriel, RS. Posteriormente foram conduzidos ao Laboratório de Bioquímica na Universidade Federal do Pampa (Unipampa) - Campus São Gabriel onde foram despolpados manualmente, seguido de maceração e lavagem dos frutos em peneira em água corrente, de modo a separar as sementes dos frutos, sendo as sementes 
colocadas para secar a sombra e sobre papel filtro, eliminando as sementes imaturas, deterioradas ou danificadas por insetos.

O lodo utilizado foi obtido das Estações de Tratamento de Água e de Esgoto São Gabriel Saneamento, São Gabriel, RS, sendo previamente higienizados pelo processo de solarização, durante 40 dias.

Os tratamentos foram compostos por 4 substratos, sendo:

S1) $100 \%$ substrato comercial Plantmax ${ }^{\circledR}$;

S2) $50 \%$ substrato comercial Plantmax ${ }^{\circledast}+50 \%$ substrato cama de equino (casca de arroz + esterco equino);

S3) $50 \%$ substrato comercial Plantmax ${ }^{\circledR}+50 \%$ resíduo orgânico de esgoto do saneamento básico;

S4) 50 \% substrato comercial Plantmax ${ }^{\circledR}+50$ \% resíduo orgânico da estação de tratamento de água.

Após a composição dos tratamentos foram avaliados os seguintes parâmetros nos substratos, antes do cultivo: $\mathrm{pH}, \mathrm{H}+\mathrm{Al}$, teor de alumínio (Al), capacidade de troca catiônica (CTC), teor de argila (A), matéria orgânica (M.O.), textura (T), nitrogênio (N), carbono total (C) de cada substrato utilizado (Tabela 1) e teores dos nutrientes $\mathrm{Ca}, \mathrm{Mg}, \mathrm{P}, \mathrm{K}, \mathrm{Zn} \mathrm{Cu}, \mathrm{S}, \mathrm{B}, \mathrm{Fe}, \mathrm{Mn}$ e $\mathrm{N}$ dos quatro substratos (Tabela 2), sendo as análises realizadas no Laboratório de Solos da Universidade Federal de Santa Maria (UFSM), Santa Maria, RS.

Tabela 1: Resultados da análise físico-química dos substratos utilizados no experimento com pitangueira (Eugenia uniflora L.), Laboratório de Solos, Universidade Federal de Santa Maria (UFSM), Santa Maria, RS, Brasil.

$$
\begin{array}{llllllll}
\mathrm{pH} & \mathrm{A} & \mathrm{T} & \mathrm{M} . \mathrm{O} & \mathrm{H}+\mathrm{Al} & \mathrm{Al} & \mathrm{CTC} & \mathrm{C}
\end{array}
$$

Trat.

\begin{tabular}{ccccccccc} 
& $\mathrm{H}_{2} \mathrm{O}$ & & & (\%) & $\begin{array}{c}\mathrm{cmol}_{\mathbf{c}} \\
\mathrm{L}^{-1}\end{array}$ & & $\mathrm{mg} \mathrm{L}^{-1}$ & $\%$ \\
\hline $\mathrm{S} 1$ & 6,4 & 6 & 4 & 21 & 2,2 & 66,3 & 88 & 16,76 \\
$\mathrm{~S} 2$ & 6,3 & 4 & 4 & 21 & 2,8 & 203,6 & 124 & 18,33 \\
$\mathrm{~S} 3$ & 6,5 & 4 & 4 & 21 & 2,5 & 116,5 & 128 & 17,38 \\
$\mathrm{~S} 4$ & 6,5 & 7 & 4 & 21 & 3,9 & 500,0 & 112 & 16,52 \\
\hline
\end{tabular}

S1) $100 \%$ substrato comercial Plantmax ${ }^{\circledR}$; S2) $50 \%$ substrato comercial Plantmax ${ }^{\circledR}+50 \%$ substrato cama de equino (casca de arroz + esterco equino); S3) $50 \%$ substrato comercial Plantmax ${ }^{\circledR}+50 \%$ resíduo orgânico de esgoto do saneamento básico; S4) 50 \% substrato comercial Plantmax ${ }^{\oplus}+50$ \% resíduo orgânico da estação de tratamento de água. 
Tabela 2: Resultados da análise de macro e micronutrientes dos substratos utilizados no experimento com pitangueira (Eugenia uniflora L.), Laboratório de Solos, Universidade Federal de Santa Maria (UFSM), Santa Maria, RS, Brasil.

\begin{tabular}{|c|c|c|c|c|c|c|c|c|c|c|c|}
\hline \multirow{2}{*}{ Trat. } & $\mathrm{Ca}$ & Mg & K & $\mathbf{P}$ & $\mathrm{Zn}$ & $\mathrm{Cu}$ & $S$ & B & $\mathrm{Fe}$ & $M n$ & \multirow{2}{*}{ \% } \\
\hline & \multicolumn{3}{|c|}{$\mathrm{cmol}_{\mathrm{c}} \mathrm{L}^{-1}$} & \multicolumn{7}{|c|}{$\mathrm{mg} \mathrm{L}^{-1}$} & \\
\hline \multirow[t]{2}{*}{ S1 } & 14,48 & 10,0 & 88 & 66 & 2,109 & 0,35 & 11,3 & 0,5 & 3725 & 14,57 & 0,603 \\
\hline & 2 & 6 & & 3 & & 6 & & & 8 & & \\
\hline \multirow[t]{2}{*}{ S2 } & 14,12 & 8,32 & 124 & 203 & 4,531 & 0,36 & 11,3 & 0,7 & 25,7 & 17,61 & 0,228 \\
\hline & 9 & & & 6 & & 1 & & & & & \\
\hline \multirow[t]{2}{*}{ S3 } & 16,40 & 10,3 & 128 & 116 & 3,673 & 0,42 & 13,4 & 0,5 & 4736 & 16,96 & 0,694 \\
\hline & 3 & 7 & & 5 & & 7 & & & 4 & & \\
\hline \multirow[t]{2}{*}{ S4 } & 16,36 & 8,75 & 112 & 500 & 70,91 & 0,70 & 11,8 & 0,5 & 7202 & 12,58 & 1,043 \\
\hline & 1 & & & & 7 & 4 & & & 5 & & \\
\hline
\end{tabular}

S1) $100 \%$ substrato comercial Plantmax ${ }^{\circledR}$; S2) $50 \%$ substrato comercial Plantmax ${ }^{\circledast}+50 \%$ substrato cama de equino (casca de arroz + esterco equino); S3) $50 \%$ substrato comercial Plantmax ${ }^{\circledR}+50 \%$ resíduo orgânico de esgoto do saneamento básico; S4) 50 \% substrato comercial Plantmax ${ }^{\circledR}+50 \%$ resíduo orgânico da estação de tratamento de água.

A semeadura foi realizada em tubetes de polietileno contendo 50 células de $200 \mathrm{~cm}^{3}$ cada, contendo uma semente por tubete, dispostas em bancadas metálicas a $100 \mathrm{~cm}$ de altura do solo. A irrigação foi realizada diariamente, visando manter a umidade dos substratos, contribuindo na germinação, e posteriormente emergência das plântulas.

A cada três dias durante os primeiros 90 dias após a emergência da primeira plântula foi calculado o índice de velocidade de emergência de acordo com a fórmula de Maguire (1962):

IVE $=\left(G_{1} / N_{1}\right)+\left(G_{2} / N_{2}\right)+\ldots+(G n / N n)$

Em que: IVE = Índice de velocidade de emergência;

$\mathrm{G} 1, \mathrm{G}_{2}, \mathrm{Gn}=$ número de sementes germinadas na primeira, segunda e última contagem; $N_{1}, N_{2}, N n=$ dias após a semeadura na primeira, segunda e última contagem.

Decorridos 180 dias após a semeadura, foi mensurada a porcentagem de emergência de acordo com Labouriau e Valadares (1976), na qual Emergência (\%) $=\mathrm{Ns} / \mathrm{Ni} \times 100$, em que: Ns = número de sementes semeadas, e $\mathrm{Ni}$ = número de plântulas que emergiram. Também foram mensuradas as seguintes características morfométricas das mudas: altura da parte aérea (CPA): com auxílio de uma régua graduada em $\mathrm{cm}_{\text {plântula }}{ }^{-1}$, diâmetro do caule (DC): com paquímetro digital expresso em $\mathrm{mm}$, número de folhas (NF): computado de modo manual, massas frescas da parte aérea (MFPA), do sistema radicular (MFR), e total (MFT): mensurada em balança digital após lavagem das mudas em água corrente, e suas respectivas massas frescas (MSPA, MSR, E MST): após a secagem em estufa com circulação de ar a 60드, por 168 horas, sendo os resultados de ambas, expresso em $\mathrm{g}_{\text {plântula }}{ }^{-1}$.

O Índice de Qualidade de Dickson (IQD), foi calculado de acordo com a proposta de Dickson et al. (1960).

IQD $=[\mathrm{MST}(\mathrm{g}) / \mathrm{CPA}(\mathrm{cm})] /[\mathrm{DC}(\mathrm{mm})+\mathrm{MSPA}(\mathrm{g}) / \mathrm{MSR})(\mathrm{g})]$

Em que: 
ÍQD = índice de qualidade de Dickson.

MST = massa seca total; $\mathrm{H}=$ altura; $\mathrm{DC}=$ diâmetro do coleto; $\mathrm{MSPA}=$ massa seca da parte aérea; $M S R$ = massa seca da raiz.

Os dados foram submetidos à análise de variância, e quando significativos pelo teste $\mathrm{F}$, as médias foram comparadas pelo teste Tukey ao nível de $5 \%$ de probabilidade de erro, utilizando o software estatístico ESTAT, versão 2, (Estat, 1994) desenvolvido pela FCAV/UNESP, Jaboticabal.

\section{Resultados e discussões}

Os resultados das análises dos quatro substratos, apresentados na Tabela 1, revelam que o teor de matéria orgânica, teor de argila e textura não diferiram entre os substratos. 0 maior teor de alumínio foi encontrado no substrato contendo resíduo proveniente do tratamento de água (S4), sendo quase cinco vezes maior do encontrado no substrato contendo resíduo proveniente do tratamento de esgoto (S3) (Tabela 1).

$\mathrm{O} \mathrm{pH}$ dos quatro substratos testados ficaram próximo ou igual a 6,5 , sendo que a faixa considerada adequada para o desenvolvimento das mudas, de 5,5 a 6,5, segundo Valeri e Corradini (2000), Kerbauy (2008) e Taiz e Zeiger (2013). O pH nesta favorece a disponibilidade de fósforo e potássio, este primeiro macronutriente encontrado em alta concentração do substrato que continha lodo da estação de água (Tabela 2).

Os resultados apresentados na tabela 2 indicam que os substratos provenientes do lodo do tratamento de esgoto e de água (S3 e S4, respectivamente) contém teores de macronutrientes que podem ser utilizados na composição dos substratos para produção de mudas em sementeiras. De acordo com Taiz e Zeiger (2013), nitrogênio e fósforo são nutrientes altamente requeridos nos estádios iniciais de desenvolvimento das mudas. 0 nitrogênio é necessário para a síntese de clorofila e, como parte da molécula da clorofila, está envolvido no processo fotossintético; é um componente do sistema enzimático, sendo essencial para a formação de aminoácidos e proteínas das mudas. Em todos os quatro diferentes substratos, a concentração de fósforo é menor que a de nitrogênio, todavia, as mudas necessitam, para seu desenvolvimento, de quantidades menores de fósforo em relação ao nitrogênio (Faustino et al., 2005).

As características morfológicas e os índices de qualidade das mudas avaliadas nesse experimento apresentaram respostas distintas entre si. Pela análise de variância observou-se efeito significativo dos substratos em todas as características analisadas, exceto para o percentual de emergência (Tabela 3 ). 
Tabela 3: Médias e respectivos erros padrão para as variáveis índice de velocidade de emergência (IVE), percentagem de emergência (E), número de folhas (NF), altura da parte aérea $(\mathrm{H})$, comprimento do sistema radicular (CSR), diâmetro do caule (DC), relação altura/diâmetro (H/DC) e índice de qualidade de Dickson (IQD) de mudas de Eugenia uniflora $\mathrm{L}$. em diferentes tipos de substratos. UNIPAMPA, São Gabriel - RS, Brasil.

\begin{tabular}{|c|c|c|c|c|c|c|c|c|}
\hline Trat. & IVE & $E(\%)$ & NF & $\mathrm{H}(\mathrm{cm})$ & $\operatorname{CSR}(\mathrm{cm})$ & $\mathrm{DC}(\mathrm{mm})$ & $H / D C$ & IQD \\
\hline \multirow[t]{2}{*}{ S1 } & $9,16 \pm 1$ & $68,8 \pm 5$ & $5,82 \pm 0,3$ & $6,44 \pm 0$ & $10,25 \pm 0$ & $0,99 \pm 0,0$ & $6,50 \pm 0$ & $0,44 \pm 0$ \\
\hline & $00 a b$ & 09 a & $8 b$ & $23 \mathrm{~b}$ & $23 a$ & $3 b$ & $70 a$ & $13 b$ \\
\hline \multirow[t]{2}{*}{ S2 } & $11,42 \pm$ & $84,8 \pm 8$ & $6,39 \pm 0,4$ & $5,04 \pm 0$ & $8,44 \pm 0,0$ & $0,89 \pm 0,0$ & $5,54 \pm 0$ & $0,72 \pm 0$ \\
\hline & $1,41 \mathrm{a}$ & $67 \mathrm{a}$ & $0 \mathrm{~b}$ & $09 \mathrm{c}$ & $9 a b$ & $3 b$ & $93 a b$ & ,09 a \\
\hline \multirow[t]{2}{*}{ S3 } & $7,17 \pm 1$ & $84,8 \pm 2$ & $5,41 \pm 0,3$ & $4,78 \pm 0$ & $9,32 \pm 0,3$ & $0,91 \pm 0,0$ & $5,23 \pm 0$ & $0,72 \pm 0$ \\
\hline & $14 \mathrm{bc}$ & $13 a$ & $0 \mathrm{~b}$ & $34 \mathrm{c}$ & $4 a$ & $3 b$ & $47 \mathrm{~b}$ &, $08 \mathrm{a}$ \\
\hline \multirow[t]{2}{*}{ S4 } & $8,7 \pm 1,21$ & $76,8 \pm 7$ & $14,13 \pm 0$ & $11,23 \pm 0$ & $8,40 \pm 0,1$ & $1,71 \pm 0,0$ & $6,57 \pm 0$ & $0,44 \pm$ \\
\hline & $b$ & $16 a$ & $50 \mathrm{a}$ & ,28 a & $4 \mathrm{~b}$ & $1 \mathrm{a}$ & $31 \mathrm{a}$ & $0,12 b$ \\
\hline CV (\%) & 14,59 & 7,85 & 11,32 & 7,36 & 6,59 & 7,50 & 1,58 & 1,04 \\
\hline
\end{tabular}

S1) $100 \%$ substrato comercial Plantmax ${ }^{\circledR}$; S2) $50 \%$ substrato comercial Plantmax ${ }^{\circledR}+50 \%$ substrato cama de equino (casca de arroz + esterco equino); S3) $50 \%$ substrato comercial Plantmax ${ }^{\circledR}+50 \%$ resíduo orgânico de esgoto do saneamento básico; S4) 50 \% substrato comercial Plantmax ${ }^{\oplus}+50$ \% resíduo orgânico da estação de tratamento de água. Médias seguidas pelas mesmas letras nas colunas não diferem significativamente pelo teste Tukey a $5 \%$ de probabilidade.

Os maiores valores observados para IVE foram obtidos nos substratos 1 (100\% substrato comercial Plantmax ${ }^{\circledast}$ ) e S2 (50\% substrato comercial Plantmax ${ }^{\circledast}+50 \%$ substrato cama de equino) (Tabela 3). De modo análogo, Freitas et al. (2015) trabalhando com a emergência e crescimento de mudas de maracujá doce (Passiflora alata Curtis) em função de lodo de esgoto verificaram que o tratamento que continha lodo apresentou os melhores resultados no percentual germinativo e no índice de velocidade de germinação, bem como em todas as variáveis de crescimento avaliadas (comprimento do sistema radicular, altura da parte aérea, diâmetro do coleto e área foliar), diferente aos resultados encontrados no presente estudo para o IVG os melhores resultados foram verificados com o uso do substrato 2, que na sua formulação apresentou casca de arroz carbonizada. Soares et al. (2012) e Taiz e Zeiger (2013) enfatizam que o melhor desenvolvimento radicular e vegetativo pode ser obtido a partir da maior rapidez de estabelecimento, ou seja, maior IVE, sendo um processo que ocorre em função do antecipado estabelecimento da parte aérea, que permite a antecipada captação dos raios solares, com a realização da fotossíntese, desencadeando os processos fisioquímicos da planta.

O substrato composto por lodo do tratamento de água, ou seja, o substrato 4, foi o que apresentou melhores resultados estatisticamente para os parâmetros número de folhas $(14,13)$, comprimento da parte aérea $(11,23 \mathrm{~cm})$ e diâmetro do coleto $(1,71 \mathrm{~cm})$ das mudas de pitangueira (Tabela 3). De acordo com Gomes et al. (2002) e Oliveira Junior et al. (2011), a altura da planta apresenta uma boa contribuição para uma avaliação da qualidade de mudas, 
sendo essas características fáceis e viáveis de mensuração, além de não destruir as mudas. 0 diâmetro do coleto, em maiores dimensões, é uma característica desejável das mudas, porque garante maior sustentação (Tucci et al., 2007) e, Oliveira et al. (2009) enfatizam que este parâmetro deve ser utilizado como o melhor dos indicadores de padrão de qualidade das mudas, pois com base neste parâmetro, mudas delgadas, de grande altura, devem ser descartadas. Kerbauy (2008), Araújo e Sobrinho (2011) e, Taiz e Zeiger (2013) enfatizam que o número de folhas é um fator inteiramente ligado ao desenvolvimento da planta, visto que elas são o principal órgão onde ocorre à fotossíntese e, também por serem centros de reserva, fonte de auxina e cofatores de enraizamento que são translocados para a base, contribuindo, ainda, para a formação de novos tecidos, como as raízes, sendo por isso mais importante que os caules. Tais informações concordam com o presente estudo, indicando um maior crescimento das mudas com a utilização de lodo da estação de tratamento de água.

Para a relação $H / D C$ ocorreram diferenças significativas entre os quatro diferentes substratos, sendo que os substratos 1,2 e 4 contribuíram para tal característica, com valores de 6,50; 5,54 e 6,57, respectivamente, diferindo-se apenas do S3 (Tabela 3). Observa-se que, para esta característica avaliada, o substrato que lodo do tratamento de esgoto não diferiu do substrato S2 (Tabela 3). Bonnet (2002) observou relação H/DC de 13,0 em mudas de Eucalyptus viminalis produzidas em substrato contendo $60 \%$ de biossólido compostado combinado com $40 \%$ de substrato comercial a base de casca de pinus e vermiculita e de 12,9 para o substrato comercial a base de casca de pinus, podendo ser encontrado valores diferentes para este parâmetro, com utilização de diferentes substratos, entre diferentes espécies vegetais de Myrtaceae.

Para o IQD houve diferença estatística entre os substratos avaliados para mudas de pitangueira, sendo encontrado os maiores valores quando foi utilizado os substratos 2 e 3, ou seja, $50 \%$ substrato comercial Plantmax ${ }^{\circledR}+50 \%$ substrato cama de equino e $50 \%$ substrato comercial Plantmax ${ }^{\circledR}+50$ \% resíduo orgânico de esgoto, respectivamente (Tabela 3). Sendo o IQD uma importante característica morfológica ponderada (Gomes e Paiva, 2004), podendo ser bom indicador da qualidade das mudas, pois se considera para o seu cálculo a robustez e o equilíbrio da distribuição da biomassa da muda, com ajuste de vários parâmetros considerados importantes (Fonseca et al., 2000). Ainda, Johnson e Cline (1991) enfatizam que o IQD é uma medida morfológica integrada e, o valor mínimo considerado padrão para mudas florestais, recomendado por Gomes e Paiva (2004), é de 0,20, assim os valores obtidos neste estudo são maiores do que os recomendados em todos os substratos avaliados, sendo encontrado 0,44 para os substratos 1 e 4 e 0,72 para os substratos 2 e 3 (Tabela 3).

$\mathrm{Na}$ obtenção de biomassa, ocorreram diferenças significativas entre os quatro diferentes substratos, sendo que o substrato S4 contribuiu para tal característica, sendo que para os demais substratos (S1, S2 e S3) não diferiram estatisticamente (Tabela 4). 
Tabela 4: Médias e respectivos erros padrão para as variáveis massa fresca radicular (MSR), massa fresca da parte aérea (MFPA), massa fresca total (MFT), massa seca radicular (MSR), massa seca da parte aérea (MSPA), massa seca total (MST), de mudas de Eugenia uniflora L. em diferentes tipos de substratos. UNIPAMPA, São Gabriel - RS, Brasil.

\begin{tabular}{|c|c|c|c|c|c|c|}
\hline Trat. & MFR & MFPA & MFT & MSR & MSPA & MST \\
\hline & \multicolumn{6}{|c|}{ g plântula ${ }^{-1}$} \\
\hline S1 & $2,437 \pm 0,72 b$ & $3,079 \pm 0,75 b$ & $5,516 \pm 1,23 \mathrm{c}$ & $1,322 \pm 0,36 \mathrm{c}$ & $1,850 \pm 0,49 b$ & $3,172 \pm 0,74 \mathrm{c}$ \\
\hline $\mathrm{S} 2$ & $3,572 \pm 0,64 b$ & $4,031 \pm 0,58 b$ & $7,558 \pm 0,69 b$ & $2,230 \pm 0,24 \mathrm{~b}$ & $2,401 \pm 0,26 b$ & $4,630 \pm 0,49 \mathrm{~b}$ \\
\hline S3 & $3,792 \pm 0,61 b$ & $4,028 \pm 0,47 b$ & $7,812 \pm 0,96 b$ & $1,846 \pm 0,31 b c$ & $2,439 \pm 0,23 b$ & $4,286 \pm 0,50 \mathrm{bc}$ \\
\hline S4 & $12,971 \pm 1,82 \mathrm{a}$ & $20,791 \pm 2,37 \mathrm{a}$ & $33,762 \pm 3,83 a$ & $4,597 \pm 0,48 a$ & $10,113 \pm 1,14 a$ & $14,712 \pm 0,90 \mathrm{a}$ \\
\hline C.V. (\%) & 7,89 & 8,52 & 16,89 & 11,33 & 12,69 & 10,25 \\
\hline
\end{tabular}

S1) $100 \%$ substrato comercial Plantmax ${ }^{\circledast}$; S2) $50 \%$ substrato comercial Plantmax ${ }^{\circledR}+50 \%$ substrato cama de equino (casca de arroz + esterco equino); S3) $50 \%$ substrato comercial Plantmax ${ }^{\circledR}+50 \%$ resíduo orgânico de esgoto do saneamento básico; S4) 50 \% substrato comercial Plantmax ${ }^{\circledast}+50$ \% resíduo orgânico da estação de tratamento de água. Médias seguidas pelas mesmas letras nas colunas não diferem significativamente pelo teste Tukey a $5 \%$ de probabilidade.

Os resultados da Tabela 4 mostra que o tratamento S4 (50\% substrato comercial Plantmax $^{\circledR}+50$ \% resíduo orgânico da estação de tratamento de água) apresentou os resultados mais satisfatórios em relação a biomassa das mudas de pitangueira corroborando os resultados da Tabela 3, onde foi verificado mudas de pitangueira de maior número de folhas, altura e diâmetro; ainda, verificou-se que o comprimento do sistema radicular dessas mudas com o substrato 4 não foi maior que os demais substratos, mas a biomassa desta parte vegetal foi maior, podendo afirma que neste substrato 4 a biomassa do sistema radicular foi maior devido ao maior número de raízes com menor comprimento quando comparado aos demais substratos (Tabelas 3 e 4).

Os substratos S1, S2 e S3 não apresentaram diferenças significativas quanto alguns parâmetro de biomassa (MFPA, MFSR, MFT e MSPA) (Tabela 4). Para os parâmetros MSSR e MST, os substratos menos satisfatórios foram os que continham os substratos Plantmax ${ }^{\circledR}$ e o substrato que continha lodo do tratamento de esgoto, ou seja, substrato 1 e 3 , respectivamente (Tabela 4 ).

O aumento do crescimento das características morfológicas altura da parte aérea, diâmetro do coleto, número de folhas e biomassa quando utilizado o substrato que continha na sua formulação resíduo do tratamento de água (S4), pode ser explicado devido aos teores de $\mathrm{N}$ e $\mathrm{P}$ (Tabela 2) que são altamente requeridos nos estádios iniciais de crescimento das mudas (Neves et al., 1990), atuando principalmente no arranque inicial do crescimento da parte aérea. Alguns autores ressaltam que o $\mathrm{K}$ ajuda no crescimento do diâmetro do coleto proporcionando o engrossamento do caule das mudas (Valeri e Corradini, 2000). Resultados semelhantes foram observados por Faria et al. (2013) utilizando diferentes proporções de lodo de esgoto na produção de mudas de Senna alata, enfatizando também um aumento das características morfológicas. Nesse estudo, o K não afetou no crescimento em diâmetro (Tabelas 2 e 3). Ainda, Guedes et al. (2011) e Silva et al. (2017) relatam que o bom desenvolvimento das plântulas, tanto nas características morfológicas como com a biomassa pode ser explicado pelas boas características que os substratos apresentam, dentre elas a estrutura, aeração, $\mathrm{pH}$ do solo, dentre outras.

Corroborando com estes dados, Scherr et al. (2010) trabalhando com substratos à base de lodo de esgoto compostado na produção de mudas de Parapiptadenia rigida (Benth.) Brenan (gurucaia) para as mesmas variáveis testadas constataram que os melhores resultados foram obtidos com lodo de esgoto a 50 e 75 , principalmente em altura e diâmetro de coleto 
das mudas. Faustino et al. (2005) testando a viabilidade do uso de lodo de esgoto como componente do substrato para produção de mudas de Senna siamea Lam utilizaram várias proporções de lodo de esgoto e verificaram que na mistura com fibra de coco a $25 \%$ apresentou os melhores resultados no crescimento das mudas. Corroborando com estes resultados Trazzi et al. (2011), estudando crescimento das diferentes características morfológicas de mudas de Tectona grandis Linn F. com uso de diferentes resíduos orgânicos, obteve maior incremento em massa seca radicular no tratamento formulado com $60 \%$ lodo de esgoto mais 40 \% fibra de coco; já para Faria et al. (2013) trabalhando com mudas de S. alata, a melhor formulação foi $80 \%$ de lodo de esgoto com $20 \%$ de fibra de coco. No presente estudo o substrato formulado com lodo de esgoto também apresentou resultados satisfatórios para todos os parâmetros, um resíduo com elevada disponibilidade nas cidades; entretanto, os melhores resultados foram com a utilização do lodo do tratamento de água (Tabelas 3 e 4), também presente em abundância no Município. Assim, a utilização de substratos compostos com materiais renováveis, como resíduos de esgoto e água e/ou cama de equino, pode ser indicada para produção de mudas de pitangueira, sendo relevante a busca de outros resíduos ecologicamente viáveis, disponíveis e baratos para propagação de mudas.

\section{Conclusões}

A aplicação de lodo de esgoto do tratamento de água como substrato favorece o desenvolvimento vegetativo e aquisição de biomassa das mudas de Eugenia uniflora.

O uso do composto do tratamento de água como componente de substratos para a produção de mudas pode ser uma alternativa viável para sua disposição final e constitui uma ferramenta a ser utilizada pelas prefeituras, na arborização urbana e recuperação de áreas degradadas.

\section{Referências}

1. ABREU, N. A. A.; MENDONÇA, V.; FERREIRA, B. G.; TEIXEIRA, G. A.; SOUZA, H. A.; RAMOS, J. D. Crescimento de mudas de pitangueira (Eugenia uniflora L.) em substratos com utilização de superfosfato simples. Ciência e Agrotecnologia, Lavras, v. 29, n. 6, p. 1117$1124,2005$.

2. AleXANDRE, H. V.; FIGUEIRÊDO, R. F.; QUEIROZ, A. J. M.; OlIVEIRA, E. N. A. Armazenamento de pitanga em pó. Comunicata Scientiae, Bom Jesus, v. 4, n. 4, p. 377384, 2014.

3. ARAÚJO, A. P.; SOBRINHO, S. P. Germinação e produção de mudas de tamboril (Enterolobium contortisiliquum (Vell.) Morong) em diferentes substratos. Revista Árvore, Viçosa, v. 35, n. 3, p. 581-588, 2011.

4. BONNET, B. R. P.; WISNIEWSKI, C.; REISSMANN, C. B.; NOGUEIRA, A. C.; ANDREOLI, C. V.; BARBIERI, S. J. Effects of substracts composed of biosolids on the production of Eucalyptus viminalis, Schinusterebinthifolius and Mimosa scabrella seedlings and on the nutritional status of Schinusterebinthifolius seedlings. Water Science and Technology, London, v. 46, n. 10, p.239-246, 2002.

5. CALDEIRA, M. V. W.; FAVALESSA, M.; GONÇALVES, E. O.; DELARMELINA, W. M.; SANTOS, F. E. V.; VIERA, M. Lodo de esgoto como componente de substrato para produção de mudas de Acacia mangium Wild. Comunicata Scientiae, Bom Jesus, v. 5, n. 1, p. 34-43, 2014. 

(Boletim técnico, 113). 2002.

7. ELLI, E. F.; CARON, B. O.; MONTEIRO, G. C.; PAVAN, M. A.; PEDRASSANI, M.; CANTARELLI, E. B.; ELOY, E. Osmocote ${ }^{\circledR}$ no desenvolvimento e comportamento fisiológico de mudas de pitangueira. Comunicata Scientiae, Bom Jesus, v. 4, n. 4, p. 377-384, 2013.

DICKSON, A.; LEAF, A. L.; HOSNER, J. F. Quality appraisal of white spruce and white pine seedling stock in nurseries. Forestry Chronicle, Mattawa, v. 36, n.1, p. 10-13, 1960.

ESTAT - Sistema de Análise Estatística (ESTAT 2.0). Jaboticabal: Pólo Computacional do Departamento de Ciências Exatas da UNESP. 1994. Comunicata Scientiae, Bom Jesus, v. 4, n. 4, p. 342-351, 2013.

11. FAUSTINO, R.; KATO, M. T.; FLORÊNCIO, L.; GAVAZZA, S. Lodo de esgoto como substrato na produção de Senna siamea Lam. Revista Brasileira de Engenharia Florestal, Campina Grande, v. 9, n. 1, p. 278-282, 2005.

12. FONSECA, E. P. Padrão de qualidade de mudas de Trema mícrantha (L.) Blume., Cedrela fissilis Vell. eAspidosperma polyneuron Müll. Arg. produzidas sob diferentes períodos de sombreamento.113 p.(Tese de Doutorado) - Universidade Estadual Paulista, Jaboticabal, Brasil. 2000.

13. FREITAS, A. R.; LOPES, J. C.; ALEXANDRE, R. S.; VENANCIO, L. P.; ZANOTTI, R. F. Emergência e crescimento de mudas de maracujá doce em função de lodo de esgoto e luz. Comunicata Scientiae, Bom Jesus, v.4, n. 4, p. 342-351, 2005.

14. GOMES, J. M.; COUTO, L.; LEITES, H. G.; XAVIER, A.; GARCIA, S. L. R. Parâmetros morfológicos na avaliação da qualidade de mudas de Eucalyptus grandis. Revista Árvore, Viçosa, v. 26, n. 6, p. 655-664, 2002.

15. GOMES, J. M.; PAIVA, H. N. Viveiros florestais: propagação sexuada. Viçosa: UFV, p.116. 2004.

16. GUEDES, R. S.; ALVES, E. U.; GONÇALVES, E. P.; FRANÇA, P. R. C.; MOURA, M. F.; SANTOS, S. S. Germinação de sementes de Dalbergia nigra (Vell.) Fr. All. Acta Scientiarum Biological Sciences, Maringa, v. 33, n. 4, p. 445-450, 2011.

17. JOHNSON, J. D.; CLINE, P. M. Seedling quality pines. In: Duryea, M. L., Dougherty, P. M. (Eds.). Forest regeneration manual. Kluwer Academic Press, Netherlands. p. 143-159, 1991.

18. KÄMPF, A. N.; FERMINO, M.H. Substratos para plantas: a base da produção vegetal em recipientes. Gênesis: Porto Alegre, Brasil. 312 p. 2000.

19. KERBAUY, G. B. Fisiologia vegetal. 2. ed. Rio de Janeiro: Guanabara Koogan, 446 p. 2008. 

Anais da Academia Brasileira de Ciências, Rio de Janeiro, v. 48, n. 2, p. 263-184, 1976. Recife: IPA, v. 87, p. 2007.

LORENZI, H. Árvores Brasileiras: manual de identificação e cultivo de plantas arbóreas nativas do Brasil. Nova Odessa: Instituto Plantarum, 384 p. 2008.

23. MAGUIRE, J. D. Speed of germination-aid in selection evaluation for seedling emergence and vigour. Crop Science, Madison, v. 1, n. 1, p. 176-177, 1962.

24. MENDONÇA, V.; MELO, J. K. H.; MENDONÇA, L. F. M.; LEITE, G. A.; PEREIRA, E. C. Avaliação de diferentes substratos na produção de portaenxertos de tamarindeiro. Revista Caatinga, Mossoró, v. 27, n. 1, p. 60-66, 2014.

NEVES, J. C. L.; GOMES, J. M.; NOVAIS, R. F. de. Fertilização mineral de mudas de eucalipto. In: BARROS, N. F.; NOVAIS, R. F. (Ed.). Relação soloeucalipto, Folha de Viçosa, Viçosa, Brasil. p.99-126, 1990.

26. OlIVEIRA, A. B. D. E.; MEDEIROS FILHO, S.; BEZERRA, A. M. E. Efeito do tamanho da semente, substrato e o ambiente na produção de mudas de Copernicia hospita Martius. Ciência e Agrotecnologia, Lavras, v.33, n. 6, p. 1527-1533, 2009.

27. OLIVEIRA JÚNIOR, O. A.; CAIRO, P. A. R.; NOVAES, A. B. Características morfofisiológicas associadas à qualidade de mudas de Eucalyptus urophylla produzidas em diferentes substratos. Revista Árvore, Viçosa, v. 35, n. 6, p. 1173-1180, 2011.

PEÑA, M. L.; ZANETTE, F.; BIASI, L. A. Miniestaquia a partir de minicepas originadas por enxertia de pitangueira adulta. Comunicata Scientiae, Bom Jesus, v. 6, n. 3, p. 297-306, 2015.

SILVA, S. M. Pitanga. Revista Brasileira de Fruticultura, Jaboticabal, v. 28, n. 1, p.1-159, 2006.

30. SILVA, R. B.; MATOS, V. P.; FARIAS, S. G. G.; SENA, L. H. M.; SILVA, D. Y. B. O. Germinação e vigor de plântulas de Parkia platycephala Benth. Em diferentes substratos e temperaturas. Revista Ciência Agronômica, Fortaleza, v. 48, n. 1, p. 142-150, 2017.

31. SCHEER, M. B.; CARNEIRO, C.; SANTOS, K. G. dos. Substratos à base de lodo de esgoto compostado na produção de mudas de Parapiptadenia rigida (Benth.) Brenan. Scientia Forestalis, Piracicaba, v. 38, n. 88, p.637-644, 2010.

32. SIMÕES, D.; SILVA, R. B. G.; SILVA, M. R. Composição do substrato sobre o desenvolvimento, qualidade e custo de produção de mudas de Eucalyptus grandis Hill Ex. Maiden x Eucalyptus urophylla s. T. Blake. Ciência Florestal, Santa Maria, v. 22, n. 1, p. 91-100, 2012.

33. SOARES, E. R.; RUI, T. L. da; BRAZ, R. F.; KANASHIRO JUNIOR, W. K. Consumo de água pela cultura do lírio, cultivado em substratos alternativos em condições de ambiente protegido. Ciência Rural, Santa Maria, v. 42, n. 6, p. 1001-1006, 2012. 
34. TAIZ, L.; ZEIGER, E. Fisiologia vegetal. 5. ed. Porto Alegre: Artmed, 820 p. 2013.

35. TRAZZI, P. A. Substratos renováveis na produção de mudas de Tectona grandis Linn $\mathbf{F}$. 74 p. (Dissertação de Mestrado) - Universidade Federal do Espírito Santo, Alegre, Brasil. 2011.

36. TRAZZI, P. A.; CALDEIRA, M. V. W.; PASSOS, R. R.; GONÇALVES, E. O. Substratos de origem orgânica para produção de mudas de teca (Tectona grandis Linn. F.). Ciência Florestal, Santa Maria, v. 23, n. 3, p. 401-409, 2013.

37. TUCCI, M. L. S.; BOVI, M. L. A.; MACHADO, E. C.; SPIERING, S. H. Seasonal growth variation of peach palms cultivated in containers under subtropical conditions. Scientia Agrícola, Piracicaba, v.64, n. 2, p. 138-146, 2007.

38. VALERI, S. V.; CORRADINI, L. Fertilização em viveiro para produção de mudas de Eucalyptus e Pinus. In: GONÇALVES, J. L. M.; BENEDETTI, V. Nutrição e fertilização florestal. Piracicaba: IPEF, 2000. p.168-190. 2000.

39. WENDLING, I.; FERRARI, M. P.; GROSSI, F. Curso intensivo de viveiros e produção de mudas. Colombo:Embrapa Florestas. 48 p. 2002. 